\title{
PERCEPTIONS OF SMALL-SCALE MAIZE FARMERS ON CLIMATE CHANGE IMPACTS IN HHOHHO, MANZINI AND SHISELWENI REGIONS OF THE KINGDOM OF ESWATINI
}

\author{
KunENE, M. N. - MTHOMBENI, D. L. ${ }^{*}-$ AnTwi, M. A. \\ Department of Agriculture and Animal Health, College of Agriculture and Environmental \\ Sciences, University of South Africa, 1710 Florida, South Africa \\ *Corresponding author \\ e-mail:mthomdl@unisa.ac.za \\ (Received 15 $5^{\text {th }}$ Feb 2019; accepted 10 ${ }^{\text {th }}$ Apr 2019)
}

\begin{abstract}
The study examined the perceptions of small-scale maize farmers in the Kingdom of eSwatini regarding the impacts of climate change. These perceptions were assessed by means of a five-point Likert scale; $59 \%$ of the respondents strongly agreed and $41 \%$ agreed that climate change has a significant influence on maize production and low yield. Multi-stage sampling involving purposive and random sampling was used in the study. The study was based on data from 188 small-scale maize farmers supplying the National Maize Corporation (NMC) depots in eSwatini. Principal component analysis (PCA) was used to analyse the data, and four factors that farmers perceived as influencing climate change were identified. The conclusion reached was that any adaptation strategies developed by smallholder maize farmers to combat climate change were largely influenced by the farmers' perceptions of climate change.
\end{abstract}

Keywords: principal component analysis, maize, National Maize Corporation, climate change, eSwatini

\section{Introduction}

Maize is a staple food in the Kingdom of eSwatini, and most small-scale farmers cultivate this crop, which is their most important source of income. Maize is highly susceptible to climate change (Sutcliffe et al., 2016); the small-scale farmers who participated in the study mentioned heat waves, drought, floods, water scarcity and plant diseases as the main factors affecting their maize production and associated these phenomena with climate change. The perceptions of small-scale maize farmers with regard to external influences are an important element determining their decisions and course of action. However, limited research has been conducted into the perceptions of maize farmers in the Kingdom of eSwatini relating to climate change. According to Debela et al. (2015), many of the studies on perceptions regarding climate change are aimed at better understanding the extent of farmers' perceptions but fail to identify the factors that influence the level at which small-scale farmers perceive climate change and its impact. Small-scale farmers and the general population find it necessary to make decisions every day concerning how to cope with and adapt to the impacts of climate change in both agricultural production and their daily lives. In eSwatini, smallholder maize farmers are already experiencing the unfavourable effects of climate change, and the impact of this phenomenon is already being felt across the socio-economic and agricultural sectors. The degree of vulnerability of communities to the effects of climate change has increased sharply, and this has negatively affected various sectors of the economy such as agriculture, water, energy, health and forestry. Establishing the perceptions of small-scale maize farmers is necessary for informed policy decisions and mitigation strategies among farmers, hence the study objective of investigating the 
perceptions of small-scale maize farmers in the Hhohho, Manzini and Shiselweni regions of eSwatini as these related to the impact of climate change.

\section{Literature review}

Sub-Saharan Africa is expected to have rainfall above the global average, yet rainfall is declining. There is growing evidence that extreme events, such as drought and floods, have been common occurrences, and these affect small-scale farmers in developing countries, who depend heavily on rainfed agriculture for their livelihoods (Belay et al., 2017). As stated above, smallholder farmers and the general population find it necessary to make decisions every day concerning how to cope with and adapt to the impacts of climate change both in agricultural production and in their daily lives. A study by Jacobi et al. (2015) indicated that small-scale farmers are affected by the negative impacts of global climate change and that livelihood based on small-scale agriculture tends to be highly vulnerable to climate change, since these farmers have limited coping options. A better understanding of farmers' concerns and the way they perceive climate change is crucial and will assist in equipping farmers to take the correct adaptive measures (Abid et al., 2017; Ayanlade et al., 2016). Perception significantly affects the way in which farmers deal with climate-induced risks and opportunities (Debela et al., 2015).

The rapid pace of climate change has been seen to have marked effects on food availability in Swaziland, as it affects crop production (Mamba et al., 2015). Adebayo et al. (2012) have reported that smallholder maize farmers with poor resources demonstrate low levels of awareness concerning climate change, and that this in turn affects their food production. Therefore, the need to identify farmers' perceptions regarding climate change is a vital step in dealing with the impacts of this phenomenon (Abid et al., 2015).

\section{Materials and methods}

\section{Sampling and data collection}

The study reported on in this article was carried out in the Kingdom of eSwatini, previously known as the Kingdom of Swaziland. The Kingdom of eSwatini (Fig. 1) is a small, landlocked, mountainous country in southern Africa, covering an area of 17364 $\mathrm{km}^{2}$ (Mamba et al., 2015). The sample frame error was controlled by obtaining a list of the 539 maize farmers who supplied maize to National Maize Corporation (NMC) depots from 2010 to 2014. This list was obtained from the NMC in 2017, and data was collected during the period 2017 to 2018. The multi-stage sampling technique was used in the study; to involve maize farmers who produced for both consumption and for sale, purposive selection criteria were used. These criteria were very useful for identifying those farmers who supplied maize to NMC depots during the period 2012 to 2014; random sampling was then used to give each small-scale farmer a chance to be selected for questionnaire administration. According to Krejcie and Morgan, as discussed by Rahi (2017), the sample size for a population of 539 should be 217; in this study, 219 questionnaires were administered to small-scale maize farmers in the three maizeproducing regions of eSwatini, namely, Hhohho, Manzini and Shiselweni. During data capture and analysis, 31 questionnaires were found to be incomplete and invalid, and the sample size was therefore reduced to 188 respondents. 


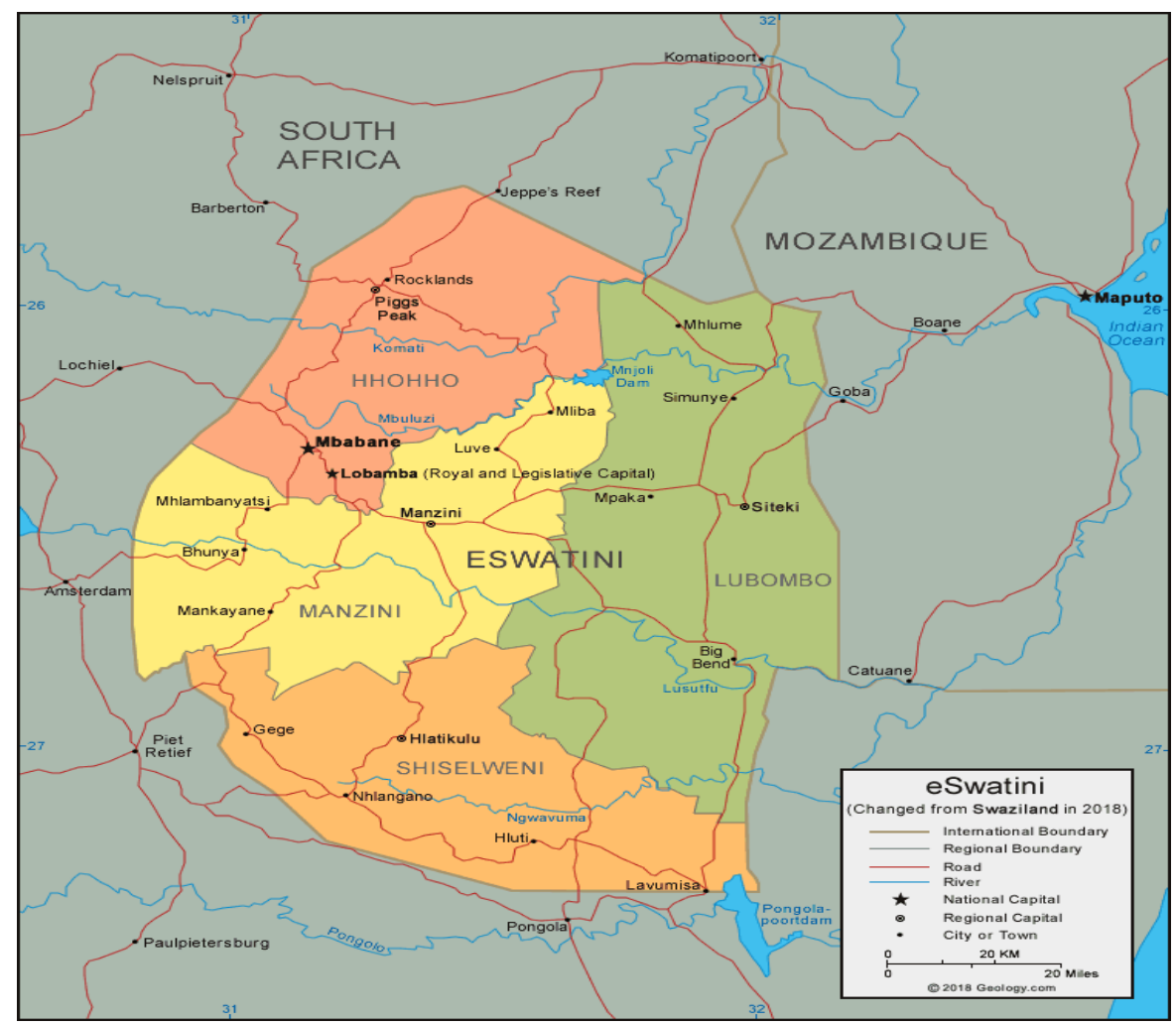

Figure 1. Map of eSwatini. (Source: https://geology.com/world/swaziland-satellite-image.shtml - accessed: 10 March 2019)

\section{Analysis of variance results}

The Kaiser-Meyer-Olkin (KMO) measure of sampling adequacy and Bartlett's test of sphericity were used to assess the appropriateness of the data for factor analysis. The Chi-square was 480.330 with 36 degrees of freedom, which was significant at ( $p<0.05$ ), as shown in Table 1. At 0.471 , the KMO measure of sampling adequacy was less than 0.50, and so factor analysis was considered an appropriate technique for further analysis of the data.

Table 1. Analysis of variance results and KMO Bartlett's test of sphericity. (Source: own calculations based on the survey (2017-2018); Kaiser-Meyer-Olkin measure of sampling adequacy $=0.471$ )

\begin{tabular}{c|c|c}
\hline Chi-square & df & Significance \\
\hline 480.330 & 36 & 0.000 \\
\hline
\end{tabular}

\section{Data analysis}

In terms of gender distribution, $47.9 \%$ of the respondents were male and $52.1 \%$ female. The respondents' perceptions were measured using a five-point Likert scale, which was applied to rank responses according to how respondents perceived climate change impact in the three maize producing regions; responses ranged as follows: 1. Strongly agree, 2. Agree, 3. Don't know 4. Disagree, and 5. Strongly disagree. A mean 
score for each variable was calculated based on questions measuring perceptions. Questions relating to how the small-scale maize farmers perceived climate change covered the following domains: incidences of floods, shifts in rainfall seasonality, persistent droughts, increasing food crop costs, destruction of buildings, infrastructure and soil erosion. A "strongly agree" score on the scale indicated a positive perception of climate change and a "strongly disagree" indicated a negative perception of climate change.

Principal component analysis (PCA) was used to rank a small number of variables that could account for the variability found in a relatively large number of variables, not including all the original variables in the analysis. This method allowed the researcher to find new variables representing the underlying or latent variables of the dataset of the statement, considered to be the factors that best described the ideas that conveyed farmers' perceptions of the impacts of climate change. Criteria such as eigenvalues greater than one and cumulative variance were explained by increasing the number of factors that were included in the factor model, and the interpretability of extracted factors was used to guide the choice of the appropriate number of factors to be included in the model of choice, or best fit model.

\section{Results and discussion}

\section{Demographic of respondents}

According to Debela et al. (2015), perceptions regarding climate change among small-scale farmers and rural communities is driven by multiple forces, such as household demographics and farm factors. The demographics of the respondents are presented in Table 2.

Table 2. Summary of demographics. (Source: own calculations based on the survey (20172018), $N=188$ )

\begin{tabular}{c|c}
\hline Variables & Percentages \\
\hline Age of the respondents & \\
Below the age of 25 years & $7.5 \%$ \\
25-30 years old & $3.9 \%$ \\
$31-40$ years old & $30.3 \%$ \\
$41-50$ years old & $25 \%$ \\
Over the age of 51 years & \\
\hline Educational level & $33.3 \%$ \\
No formal education & $15.4 \%$ \\
Primary education & $39.9 \%$ \\
Secondary education & $27.1 \%$ \\
Tertiary education & $17.6 \%$ \\
\hline Household size & \\
Fewer than 2 members & $11.7 \%$ \\
3-6 members & $40.4 \%$ \\
7-10 members & $36.2 \%$ \\
More than 10 members & $11.7 \%$ \\
\hline
\end{tabular}




\section{Age of the respondents}

Table 2 presents the age distribution of respondents. The age of the respondents was analysed as a reflection of their agricultural production experience. Debela et al. (2015) identified a close relationship between the age of a farmer and farming experience and his or her accumulated knowledge of the environment, including changes in climate conditions. $33.3 \%$ of the respondents were over the age of $50,30.3 \%$ of the respondents were between the ages of 31 and 40 , and $25 \%$ of the respondents were between the ages of 41 and 50. The remaining 3.9\% of the respondents were between the ages of 25 and 30. This suggests that maize farming in the Kingdom is dominated by older smallholder farmers. The results also revealed that $30.3 \%$ of the heads of households were in the productive age group of 31 to 40 and more than 51 and would therefore be in a position to take action with regard to climate change.

\section{Education level}

The distribution of respondents by education level is shown in Table 2. The highest number of respondents $(39.9 \%)$ had higher primary education, followed by secondary education (27.1\%), tertiary education (17.6\%) and non-formal education (15.4\%). Farmers with a higher level of education had slightly more knowledge and information about good agricultural principles, and those with university education were able to analyse and interpret information much better than farmers with no formal education. The results also showed that farmers with education and agricultural skills made a significant contribution in the context of maize production activities. The level of formal education attained by farmers influences their ability to perceive climate change and its impact (Debela et al., 2015).

\section{Household size}

In the maize production areas in the three regions, $11.7 \%$ of households consisted of fewer than 2 members, and a further $11.7 \%$ of households consisted of more than 10 members. $40.4 \%$ of households consisted of 3 to 6 members, and $36.2 \%$ of households comprised 7 to 10 members (Table 2). The fact that there were so many large households would be expected to have a positive impact on maize production when all household members were fully engaged in agricultural activities. The results also showed that as the number of household members increased, so did the chances that the household was engaged in agricultural production, since it would be possible to take advantage of a readily available labour force, and the chances of adapting to climate change impact would therefore be high. According to Debela et al. (2015), households consisting of many members are more likely to engage in non-farm income generating activities, because non-farm income buffers financial losses from farming; in consequence, householders are less likely to perceive climate change.

\section{Percentage ratings of the perceptions regarding climate change impact}

Table 3 presents the descriptive statistics of the variables that indicated perceptions of climate change. About $59 \%$ of the respondents perceived climate change to have a very significant influence on maize production, while $44.7 \%$ of the farmers strongly agreed that shifts in rainfall patterns have caused crop failures and low yield. 
Table 3. Percentage ratings of respondents' perceptions regarding climate change impact. (Source: own calculations based on the survey (2017-2018), N = 188)

\begin{tabular}{|c|c|c|c|c|c|}
\hline $\begin{array}{c}\text { Perceptions regarding climate change } \\
\text { impact }\end{array}$ & $\begin{array}{l}\text { Strongly } \\
\text { agree }\end{array}$ & Agree & $\begin{array}{l}\text { I do not } \\
\text { know }\end{array}$ & Disagree & $\begin{array}{l}\text { Strongly } \\
\text { disagree }\end{array}$ \\
\hline $\begin{array}{l}\text { Climate change has a very big impact on } \\
\text { maize production }\end{array}$ & $59 \%$ & $41 \%$ & $00 \%$ & $00 \%$ & $00 \%$ \\
\hline $\begin{array}{l}\text { Variations in climate have caused an } \\
\text { increase in incidences of floods }\end{array}$ & $7.4 \%$ & $12.2 \%$ & $29.3 \%$ & $16.5 \%$ & $34.6 \%$ \\
\hline $\begin{array}{l}\text { Shifts in rainfall seasonality have caused } \\
\text { crop failures and low yield }\end{array}$ & $44.7 \%$ & $34.0 \%$ & $12.2 \%$ & $4.8 \%$ & $4.3 \%$ \\
\hline $\begin{array}{l}\text { Crop varieties have no longer been } \\
\text { productive due to persistent droughts }\end{array}$ & $25.5 \%$ & $20.7 \%$ & $29.3 \%$ & $14.9 \%$ & $9.6 \%$ \\
\hline $\begin{array}{l}\text { Climate change has led to crop infestation } \\
\text { and diseases due to droughts }\end{array}$ & $7.4 \%$ & $31.9 \%$ & $37.8 \%$ & $22.9 \%$ & $00 \%$ \\
\hline $\begin{array}{l}\text { Climate change has led to rural-urban } \\
\text { migration }\end{array}$ & $00 \%$ & $15.4 \%$ & $46.3 \%$ & $24.5 \%$ & $13.8 \%$ \\
\hline $\begin{array}{l}\text { Excessive rainfall contributes to destruction } \\
\text { of buildings and infrastructure }\end{array}$ & $67.0 \%$ & $17.6 \%$ & $11.7 \%$ & $3.7 \%$ & $00 \%$ \\
\hline $\begin{array}{l}\text { Flood does not contribute to soil } \\
\text { erosion }\end{array}$ & $20.2 \%$ & $5.9 \%$ & $28.7 \%$ & $24.5 \%$ & $20.7 \%$ \\
\hline $\begin{array}{l}\text { Water becomes scarce due to droughts and } \\
\text { low rainfall }\end{array}$ & $72.3 \%$ & $20.2 \%$ & $00 \%$ & $3.2 \%$ & $4.3 \%$ \\
\hline $\begin{array}{c}\text { Dry spell of crops is the result of } \\
\text { drought }\end{array}$ & $30.9 \%$ & $45.7 \%$ & $12.2 \%$ & $3.7 \%$ & $7.4 \%$ \\
\hline $\begin{array}{c}\text { Climate variability has an impact on rain-fed } \\
\text { production }\end{array}$ & $42.0 \%$ & $10.1 \%$ & $31.9 \%$ & $7.4 \%$ & $8.5 \%$ \\
\hline $\begin{array}{c}\text { Decrease in rainfall reduces water stored in } \\
\text { bands }\end{array}$ & $27.7 \%$ & $27.7 \%$ & $3.1 .9 \%$ & $4.3 \%$ & $8.5 \%$ \\
\hline $\begin{array}{c}\text { Climate change has led to } \\
\text { deforestation }\end{array}$ & $20.7 \%$ & $31.4 \%$ & $42.0 \%$ & $3.7 \%$ & $2.1 \%$ \\
\hline $\begin{array}{l}\text { The cost of food crops is increasing because } \\
\text { of climate change }\end{array}$ & $24.5 \%$ & $36.2 \%$ & $25.0 \%$ & $4.3 \%$ & $10.1 \%$ \\
\hline
\end{tabular}

$67 \%$ of the small-scale maize farmers strongly agreed that excessive rainfall contributes to destruction of buildings and infrastructure, $72.3 \%$ strongly agreed that water becomes scarce due to droughts and low rainfall. The results further reveal that $42 \%$ of smallholder maize farmers perceived climate variability to have a significant impact on rainfed maize production. Mamba et al. (2015) reported different perceptions of climate change among farmers, further showing that these farmers tended to overestimate the negative impact of climate change, and that this misperception affected crop production.

\section{Scree plot}

In the scree plot in Figure 2, eigenvalues were plotted against principal component (PC) numbers. The PC numbers were plotted on the X-axis, while the eigenvalues were plotted on the Y-axis. The PCs that were kept were those on the slope of the graph before the decrease in eigenvalues levels off to the right of the plot. Using this criterion, 
4 PCs, namely: impact on maize production, climate change, flood incidences, shifts in rainfall and droughts were retained in the analysis of this study.

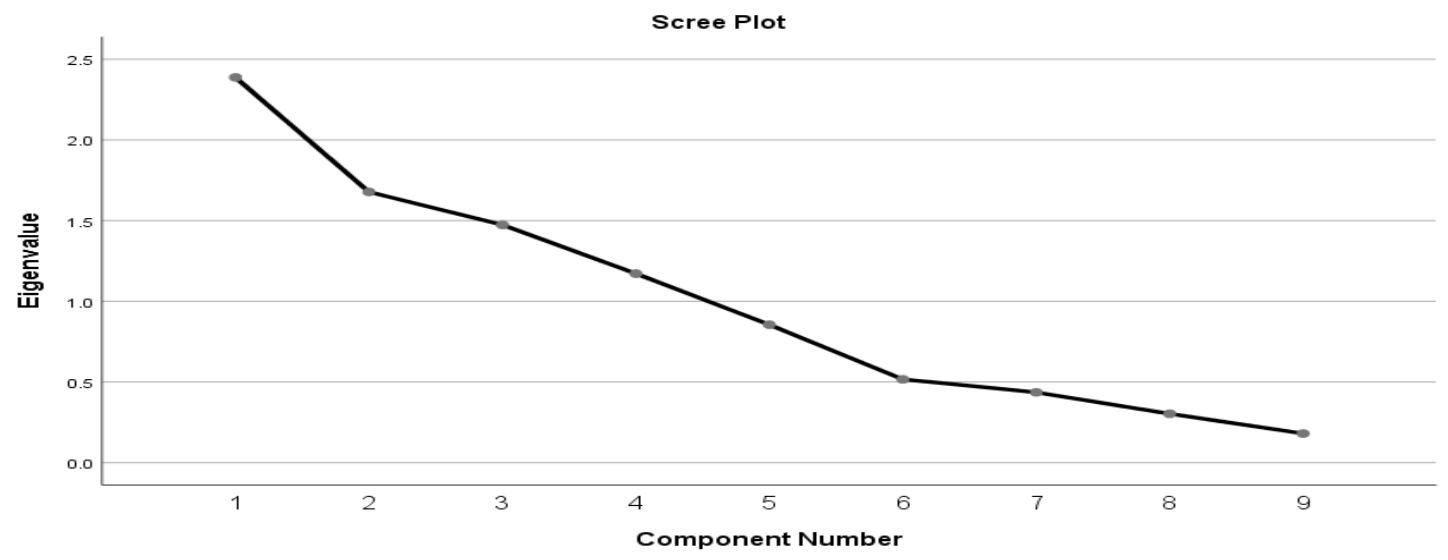

Figure 2. Scree plot

In Figure 2, the different variables represented different patterns of perceptions of small-scale maize farmers regarding climate change. The grouping of the original variables was done by observing the magnitude of the factor loadings. Each PC was considered a weighted linear combination of the variables and was written with the heavy loadings and given the most descriptive name.

\section{Cumulative column}

The eigenvalue table was divided into three sub-sections, namely Initial eigenvalues, Extracted sums of squared loadings and Rotation of sums of squared loadings. For analysis and interpretation purposes we were concerned only with the extracted sums of squared loadings. Note that the first factor accounts for $26.525 \%$ of the variance, the second $18.640 \%$, the third $16.373 \%$ and the fourth $13.017 \%$. All the remaining factors were not significant. Table 4 presents the number of principals, from which 4 were selected. The cumulative column indicates that extracting the 4 factors made it possible to explain roughly $75 \%$ of the variation in the data.

\section{Principal component factor analysis (Rotated factor pattern)}

Principal component 1 (PC1) contributed $26.525 \%$ of the variations, with an eigenvalue of 29.419, and represented small-scale farmers who were aware of the impact of climate change, such as floods, soil erosion and water scarcity between 2010 and 2014 (see the Component 1 column in Table 5). Of the four coefficients, three were positive, indicating a positive correlation among the significant variables, for instance, an increase in flood incidences will result in an increase in soil erosion; on the other hand, an increase in flood incidences decreases water scarcity. The PC1 equation is presented below:

$$
\mathrm{PC} 1=0.465 \mathrm{X}_{1}+0.754 \mathrm{X}_{2}+0.400 \mathrm{X}_{8}-0.907 \mathrm{X}_{9}
$$


Table 4. Cumulative percentages of variance. (Source: own calculations based on the survey (2017-2018), $N=188$ )

\begin{tabular}{|c|c|c|c|c|c|c|c|c|c|}
\hline \multicolumn{4}{|c|}{ Initial eigenvalues } & \multicolumn{3}{|c|}{$\begin{array}{c}\text { Extraction sums of squared } \\
\text { loading }\end{array}$} & \multicolumn{3}{|c|}{$\begin{array}{c}\text { Rotation sums of squared } \\
\text { loadings }\end{array}$} \\
\hline Variables & Total & $\begin{array}{c}\% \text { of } \\
\text { variance }\end{array}$ & $\underset{\%}{\text { Cumulative }}$ & Total & \begin{tabular}{|c|}
$\%$ of \\
variance
\end{tabular} & $\begin{array}{c}\text { Cumulative } \\
\%\end{array}$ & Total & \begin{tabular}{|c|}
$\%$ of \\
variance
\end{tabular} & $\underset{\%}{\text { Cumulative }}$ \\
\hline $\begin{array}{c}\text { Impact on } \\
\text { maize } \\
\text { production }\end{array}$ & 2.39 & 26.53 & 29.419 & 2.39 & 26.53 & 26.53 & 1.86 & 20.66 & 20.66 \\
\hline $\begin{array}{c}\text { Flood } \\
\text { incidences }\end{array}$ & 1.678 & 18.640 & 45.165 & 1.678 & 18.640 & 45.165 & 1.762 & 19.577 & 40.240 \\
\hline $\begin{array}{l}\text { Shifts in } \\
\text { rainfall }\end{array}$ & 1.474 & 16.373 & 61.537 & 1.47 & 16.373 & 61.537 & 1.671 & 18.562 & 58.802 \\
\hline Droughts & 1.171 & 13.017 & 74.554 & 1.171 & 13.017 & 74.554 & 1.418 & 15.752 & 74.554 \\
\hline $\begin{array}{c}\text { Crop } \\
\text { disease }\end{array}$ & 0.855 & 9.499 & 84.053 & & & & & & \\
\hline $\begin{array}{c}\text { Rural- } \\
\text { urban } \\
\text { migration }\end{array}$ & 0.516 & 5.737 & 89.790 & & & & & & \\
\hline $\begin{array}{c}\text { Structural } \\
\text { destruction }\end{array}$ & 0.436 & 4.840 & 94.630 & & & & & & \\
\hline $\begin{array}{c}\text { Soil } \\
\text { erosion }\end{array}$ & 0.303 & 3.367 & 97.996 & & & & & & \\
\hline $\begin{array}{l}\text { Water } \\
\text { scarcity }\end{array}$ & 0.180 & 2.004 & 100.000 & & & & & & \\
\hline
\end{tabular}

Table 5. Rotated factor pattern. (Source: own calculations based on the survey (20172018))

\begin{tabular}{c|c|c|c|c}
\hline Variables & Component 1 & Component 2 & Component 3 & Component 4 \\
\hline Impact on maize production $\left(\mathrm{X}_{1}\right)$ & $\mathbf{0 . 4 6 5}$ & $\mathbf{- 0 . 3 4 9}$ & 0.429 & $\mathbf{0 . 4 7 7}$ \\
Flood incidences $\left(\mathrm{X}_{2}\right)$ & $\mathbf{0 . 7 5 4}$ & -0.051 & 0.184 & -0.097 \\
Shifts in rainfall $\left(\mathrm{X}_{3}\right)$ & -0.057 & $\mathbf{0 . 2 9 8}$ & $\mathbf{- 0 . 6 4 6}$ & $\mathbf{0 . 4 0 4}$ \\
Droughts $\left(\mathrm{X}_{4}\right)$ & 0.006 & 0.080 & $\mathbf{0 . 8 6 0}$ & 0.191 \\
Crop disease $\left(\mathrm{X}_{5}\right)$ & 0.159 & $\mathbf{0 . 8 9 7}$ & 0.016 & -0.070 \\
Rural-urban migration $\left(\mathrm{X}_{6}\right)$ & 0.082 & 0.082 & $\mathbf{0 . 5 1 9}$ & -0.366 \\
Structural destruction $\left(\mathrm{X}_{7}\right)$ & -0.238 & 0.069 & -0.029 & $\mathbf{0 . 8 5 9}$ \\
Soil erosion $\left(\mathrm{X}_{8}\right)$ & $\mathbf{0 . 4 0 0}$ & $\mathbf{- 0 . 7 2 9}$ & 0.072 & -0.286 \\
Water scarcity $\left(\mathrm{X}_{9}\right)$ & $\mathbf{- 0 . 9 0 7}$ & -0.076 & 0.143 & 0.146 \\
\hline
\end{tabular}


Principal component 2 (PC2) contributed $18.640 \%$ of the variations, with an eigenvalue of 45.165 . The variables included small-scale maize farmers who were aware of the impacts of climate change on maize production, and experienced shifts in rainfall, crop diseases and soil erosion between 2010 and 2014. The results in the Component 2 column in Table 5 imply that shifts in rainfall to higher levels decreases the impact on maize production. However, an increase in shifts in rainfall increases crop diseases. The PC2 equation is presented below:

$$
\mathrm{PC} 2=-0.349 \mathrm{X}_{1}+0.298 \mathrm{X}_{3}+0.897 \mathrm{X}_{5}-0.729 \mathrm{X}_{8}
$$

Principal component 3 (PC3) contributed $16.373 \%$ of the variations, with an eigenvalue of 61.537. The variables included small-scale maize farmers who held perceptions on climate change and who had experienced a significant shift in rainfall, droughts patterns and rural-urban migration. The results in the Component 3 column in Table 5 indicate that a decrease in rainfall increases drought patterns and rural urban migration. The PC equation between 2010 and 2014 is presented below:

$$
\mathrm{PC} 3=-0.646 \mathrm{X}_{3}+0.860 \mathrm{X}_{4}+0.519 \mathrm{X}_{6}
$$

Principal component 4 (PC4) contributed to $13.017 \%$ of the variations, with an eigenvalue of 70.506. The variables included small-scale maize farmers who held perceptions on climate change and who had experienced impact on maize production, shifts in rainfall and structural destruction between 2010 and 2014. The results in the Component 4 column in Table 5 show a positive correlation among the variables. The PC equation between 2010 and 2014 is presented below:

$$
\mathrm{PC} 4=0.477 \mathrm{X}_{1}+0.404 \mathrm{X}_{3}+0.859 \mathrm{X}_{7}
$$

\section{Correlation between the explanatory variables in the analysis of variance}

To determine the degree and nature of the relationship and the direction of association among the independent and dependent variables, a correlation analysis was worked out and presented in the form of a correlation matrix. Table 6 shows a correlation or relationship between the perceptions of small-scale maize farmers regarding impacts of climate change and the independent variables: the impact on maize production, floods, shifts in rainfall, droughts, crop diseases, rural-urban migration, structural destruction, soil erosion and water scarcity. A positive relationship between perception and the independent variables was established. Of the nine independent variables, five, namely crop diseases, rural-urban migration, structural destruction, soil erosion and water scarcity, were positively and significantly correlated $(p<0.05)$ with the perceptions of farmers regarding climate change.

Table 6 shows that crop diseases were positively and significantly correlated $(p<0.373)$ with floods and droughts (0.375). This meant that farmers who perceived that crop diseases were associated with climate change had high perceptions of floods and droughts as the effects of climate change. A study conducted in Swaziland by Mamba et al. (2015) showed that the majority of farmers $(88.1 \%)$ indicated that they had noted changes in the frequency, intensity and duration of drought over the preceding years. 
Table 6. Correlation between the explanatory variable in the analysis of variance. (Source: own calculations based on the survey (2017-2018))

\begin{tabular}{l|c|c|c|c|c|c|c|c|c}
\hline \multicolumn{1}{c|}{ Variables } & $\mathbf{1}$ & $\mathbf{2}$ & $\mathbf{3}$ & $\mathbf{4}$ & $\mathbf{5}$ & $\mathbf{6}$ & $\mathbf{7}$ & $\mathbf{8}$ & $\mathbf{9}$ \\
\hline 1. Impact on maize production & 1.000 & & & & & & & & \\
2. Flood incidences & 0.002 & 1.000 & & & & & & & \\
3. Shifts in rainfall & 0.016 & 0.000 & 1.000 & & & & & & \\
4. Droughts & 0.000 & 0.003 & 0.000 & 1.000 & & & & & \\
5. Crop disease & 0.008 & $\mathbf{0 . 3 7 3}$ & 0.033 & $\mathbf{0 . 3 7 5}$ & 1.000 & & & & \\
6. Rural-urban migration & $\mathbf{0 . 3 0 5}$ & $\mathbf{0 . 3 0 7}$ & 0.005 & 0.000 & 0.000 & 1.000 & & & \\
7. Structural destruction & 0.010 & 0.000 & 0.000 & $\mathbf{0 . 2 5 0}$ & $\mathbf{0 . 2 7 4}$ & 0.001 & 1.000 & & \\
8. Soil erosion & 0.000 & 0.002 & 0.000 & 0.129 & 0.000 & 0.001 & 0.000 & 1.000 & \\
9. Water scarcity & 0.001 & 0.000 & $\mathbf{0 . 2 5 5}$ & 0.069 & 0.003 & 0.118 & 0.000 & 0.000 & 1.000 \\
\hline
\end{tabular}

$P<0.05, P<0.01, N=188$

Rural-urban migration was positively correlated (sig. 0.305) with impact on maize production and floods (0.307), and it affected the perceptions of farmers regarding climate change. The more aware the farmers were of rural-urban migration, the more they perceived maize production and floods to be effects of climate change.

The results in Table 6 showed that structural destruction was positively associated with drought at (sig. 0.250) and crop diseases at (sig. 0.274). From the results, it could be inferred that farmers who perceived structural destruction to be caused by climate change also perceived that droughts and crop diseases were caused by climate change. Water scarcity was also positively correlated with shifts in rainfall. The likelihood of water scarcity as a result of shifts in rainfall was statistically significant (sig. 0.255).

\section{Interpretation of the independent variables}

The results of descriptive statistics for all the variables under investigation is presented in Table 7. The means and the standard deviation of respondents are given. The means showed rural-urban migration, floods, soil erosion, crop diseases and droughts to be the most important variables influencing small-scale maize farmers' perceptions of climate change. These variables had the highest means, namely 3.4734 , 3.4043. 3.2340, 2.9894 and 2.6755, respectively.

Table 7. Descriptive statistics of the variables. (Source: own calculations based on the survey (2017-2018), $N=188$ )

\begin{tabular}{c|c|c}
\hline Variables & Mean & Std. deviation \\
\hline Impact on maize production & 1.4096 & 0.49307 \\
Flood incidences & 3.4043 & 1.12644 \\
Shifts in rainfall & 1.9043 & 1.08040 \\
Droughts & 2.6755 & 1.35079 \\
Crop disease & 2.9894 & 1.24096 \\
Rural-urban migration & 3.4734 & 1.02604 \\
Structural destruction & 1.5585 & 0.96560 \\
Soil erosion & 3.2340 & 1.41743 \\
Water scarcity & 1.41743 & 0.94405 \\
\hline
\end{tabular}




\section{Box plots}

Box plots were used to show patterns of responses for each group, as shown in Figure 3. They provided a useful way of visualising the range and other characteristics of responses for large groups. As an indicator of centrality, the box plot was of a sample of 5 points from a population centred on 3. As an indicator of symmetry, the box plot was a sample of 5 points from a symmetrical population.

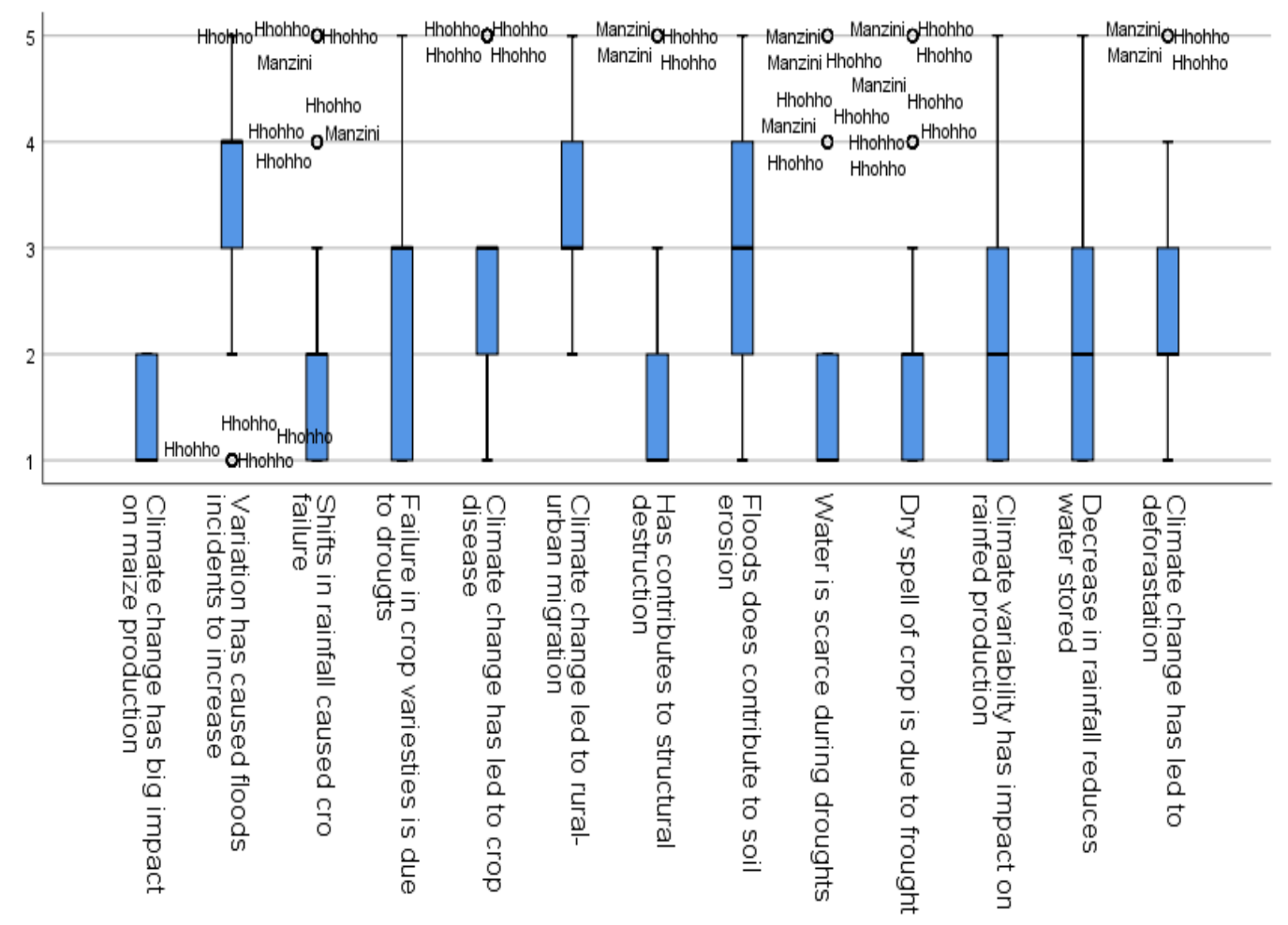

Figure 3. Box plots showing overall patterns of response for groups

The data sets for variables 1 and 9, namely impacts on maize production and water scarcity during drought, were skewed to the left with a median of 1 . Variables 2 and 6 , namely caused floods to increase and rural-urban migration, were skewed to the right and to the left, respectively. The data sets for variables 3 and 10, shift in rainfall caused crop failure and dry spells of crops due to drought, were skewed to the right. According to Debela et al. (2015), farmers perceived the onset of rainfall to be much later over the past ten years than 20 years ago, and they also perceived rainfall to cease halfway through the growing season. Variable 8, floods which contributed to soil erosion, was symmetrical. This showed that small-scale maize farmers perceived soil erosion to be a significant result of climate change.

The line for 1 variable (Floods contributes to soil erosion) is in the centre of the box, and the whisker lengths are the same. In the case of 6 variables (shift in rainfall, structural destruction, dry spells, climate variability and reduced rainfall), the top whisker is much longer than the bottom whisker, and the line gravitates towards the bottom of the box. In the case of 1 variable (climate change has led to crop failure), the bottom whisker is much longer than the top whisker, and the line rises to the top of the box. 


\section{Conclusion}

The perceptions of small-scale maize farmers regarding climate change was analysed using information from maize farmers relating to the farming seasons during the period 2010 to 2014. Results showed that farmers had different levels of perception regarding climate change. They also showed that maize production declined in the 2012 to 2014 cropping seasons. Principal component analysis revealed that it was possible to place different perception factors affecting climate change in different groups. In conclusion, smallholder maize farmers in the three regions held a range of perceptions regarding climate change. The results indicated that any adaptation strategies developed by smallholder maize farmers to combat climate change were largely influenced by their perceptions regarding climate changes. Farmers' perceptions, if well articulated, have a significant influence on how the government responds or intervenes in such situations.

\section{REFERENCES}

[1] Abid, M. E. A., Scheffran, J., Schneider, U. A., Ashfaq, M. (2015): Farmers' perceptions of and adaptation strategies to climate change and their determinants: the case of Punjab province, Pakistan. - Earth System Dynamics 6(1): 225-243.

[2] Adebayo, A. A., Onu, J. I., Adebayo, E. F., Anyanwu, S. O. (2012): Farmers' awareness, vulnerability and adaptation to climate change in Adamawa State, Nigeria. - British Journal of Arts and Social Sciences 9(2): 104-115.

[3] Ayanlade, A., Radeny, M., Morton, J. F. (2017): Comparing smallholder farmers' perception of climate change with meteorological data: a case study from southwestern Nigeria. - Weather and Climate Extremes 15: 24-33.

[4] Belay, A., Recha, J. W., Woldeamanuel, T., Morton, J. F. (2017): Smallholder farmers' adaptation to climate change and determinants of their adaptation decisions in the Central Rift Valley of Ethiopia. - Agriculture \& Food Security 6(1): 24.

[5] Debela, N., Mohammed, C., Bridle, K., Corkrey, R., McNeil, D. (2015): Perception of climate change and its impact by smallholders in pastoral/agropastoral systems of Borana, South Ethiopia. - SpringerPlus 4(1): 236.

[6] Jacobi, J., Schneider, M., Bottazzi, P., Pillco, M., Calizaya, P., Rist, S. (2015): Agroecosystem resilience and farmers' perceptions of climate change impacts on cocoa farms in Alto Beni, Bolivia. - Renewable Agriculture and Food Systems 30(2): 170-183.

[7] Mamba, S. F., Salam, A., Peter, G. (2015): Farmers' perception of climate change: a case study in Swaziland. - Journal of Food Security 3(2): 47-61.

[8] Rahi, S. (2017): Research design and methods: A systematic review of research paradigms, sampling issues and instruments development. - International Journal of Economics \& Management Sciences 6(2): 1-5.

[9] Sutcliffe, C., Dougill, A. J., Quinn, C. H. (2016): Evidence and perceptions of rainfall change in Malawi: do maize cultivar choices enhance climate change adaptation in subSaharan Africa? - Regional Environmental Change 16(4): 1215-1224. 